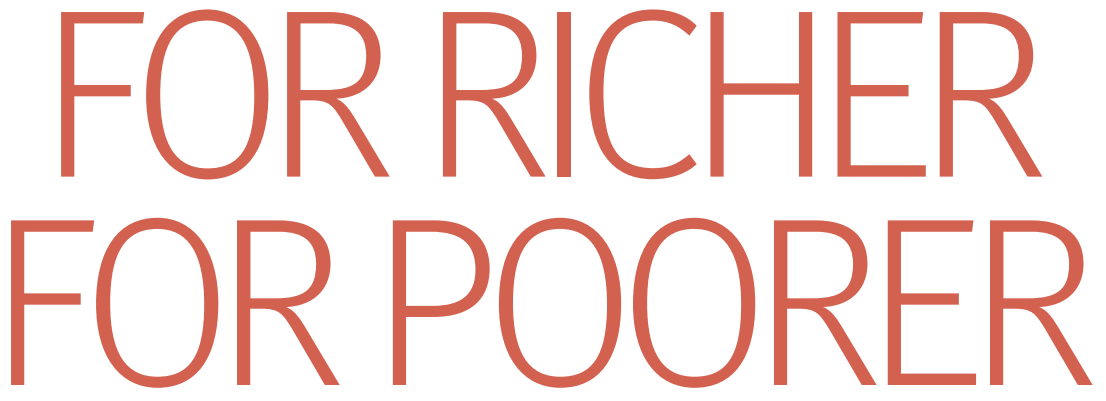

Five years ago, the world's biggest publishing houses committed themselves to letting researchers in developing countries have free access to the content of their journals. Beset by technical problems and language difficulties, is HINARI succeeding in what it set out to do? Hannah Brown reports

(a) $t$ is not often that publishers of scientific material get a good press. Their main customers-the funders of research, scientists, and librarians-have long resented the unfairness of a system that sees their library coffers squeezed dry to purchase reports about their own science, resulting in a fractious, if co-dependent, relationship. But away from the animosity of rich countries' labs and libraries, the world's biggest publishers have been challenging their heartless image.

Since 2000, when the World Health Organization (WHO) first broached the idea of increasing access to scientific information in the developing world by supplying

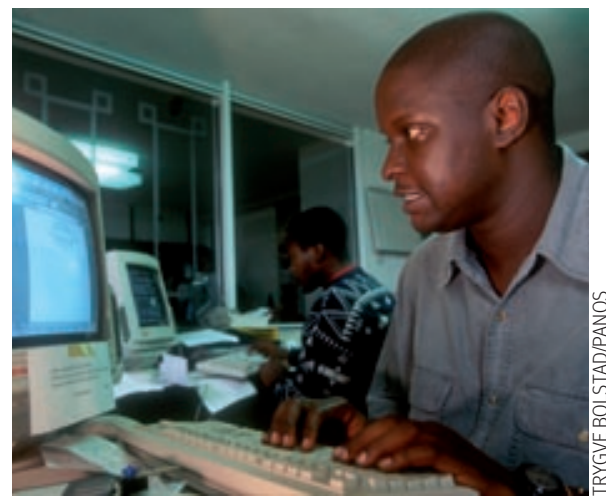

electronic content free of charge (phase 1) or at low cost (phase 2), publishers have been falling over themselves to take part. Last month, more than 100 of the world's largest publishing companies further extended their commitment to this philanthropic project by pledging to support WHO's "health internetwork access to research initiative" (HINARI) to at least 2015 . $^{1}$

Some observers question whether the industry's motives are purely altruistic. It is conceivable that pitifully poor countries in 2007 may later follow China along the path to rampant consumerism, making HINARI a useful mechanism for pre-emptive brand recognition. Nevertheless, the commitment

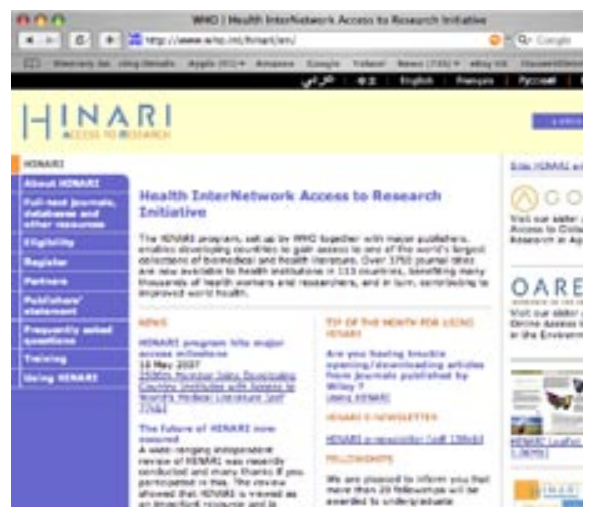

Uganda is just one of 113 countries to have benefited from HINARI

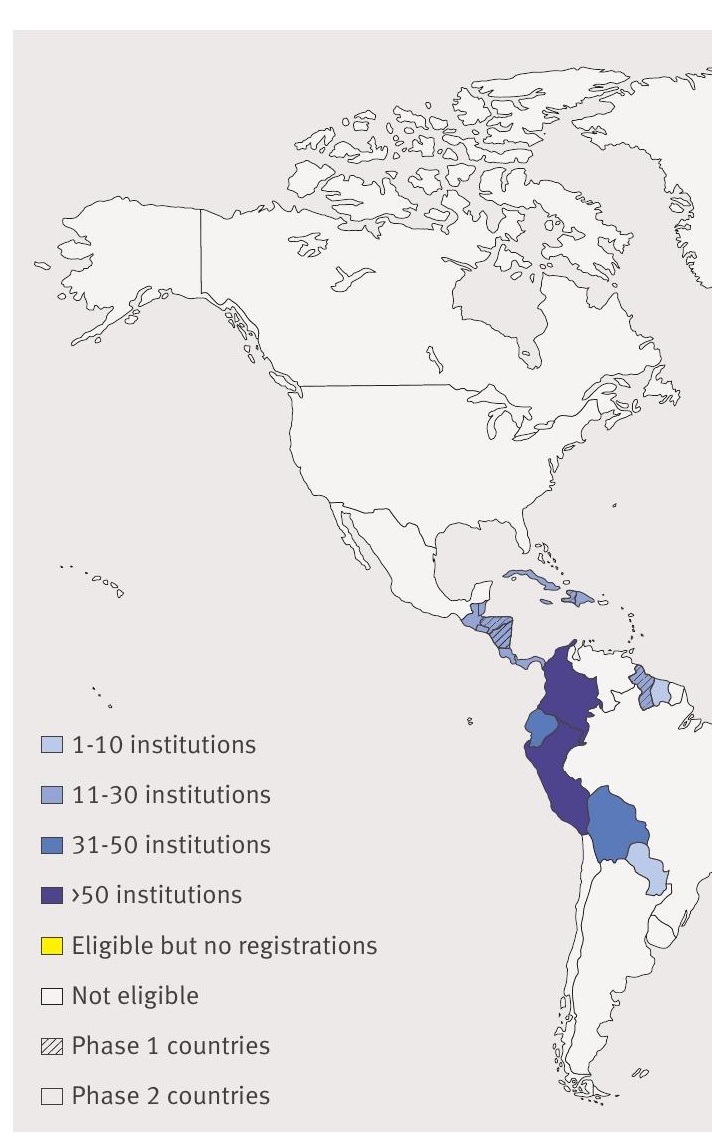

Institutions registered with HINARI

of publishers-and the rapid success they have helped HINARI achieve-has provided a valuable opportunity for scientists in developing countries to engage in the global scientific conversation.

"Developing country researchers who don't have access to the internet will put together a proposal and then get it immediately turned down by a funder, who says the proposal is out of date," explains Barbara Aronson, HINARI's project manager and one of only two full time staff working on the project based at WHO, "but when you allow these researchers access to current journals they can contribute and be involved in the biomedical research community."

\section{Access restrictions}

This opportunity, HINARI's first proponents confidently predicted, would not only improve research in developing countries but would lead to knock-on effects that boosted health outcomes and much more besides. But, five years on, HINARI has become bogged down by some of the technical challenges of delivering electronic content. Many users have internet connection speeds so slow that downloading a single article can absorb an entire afternoon. 


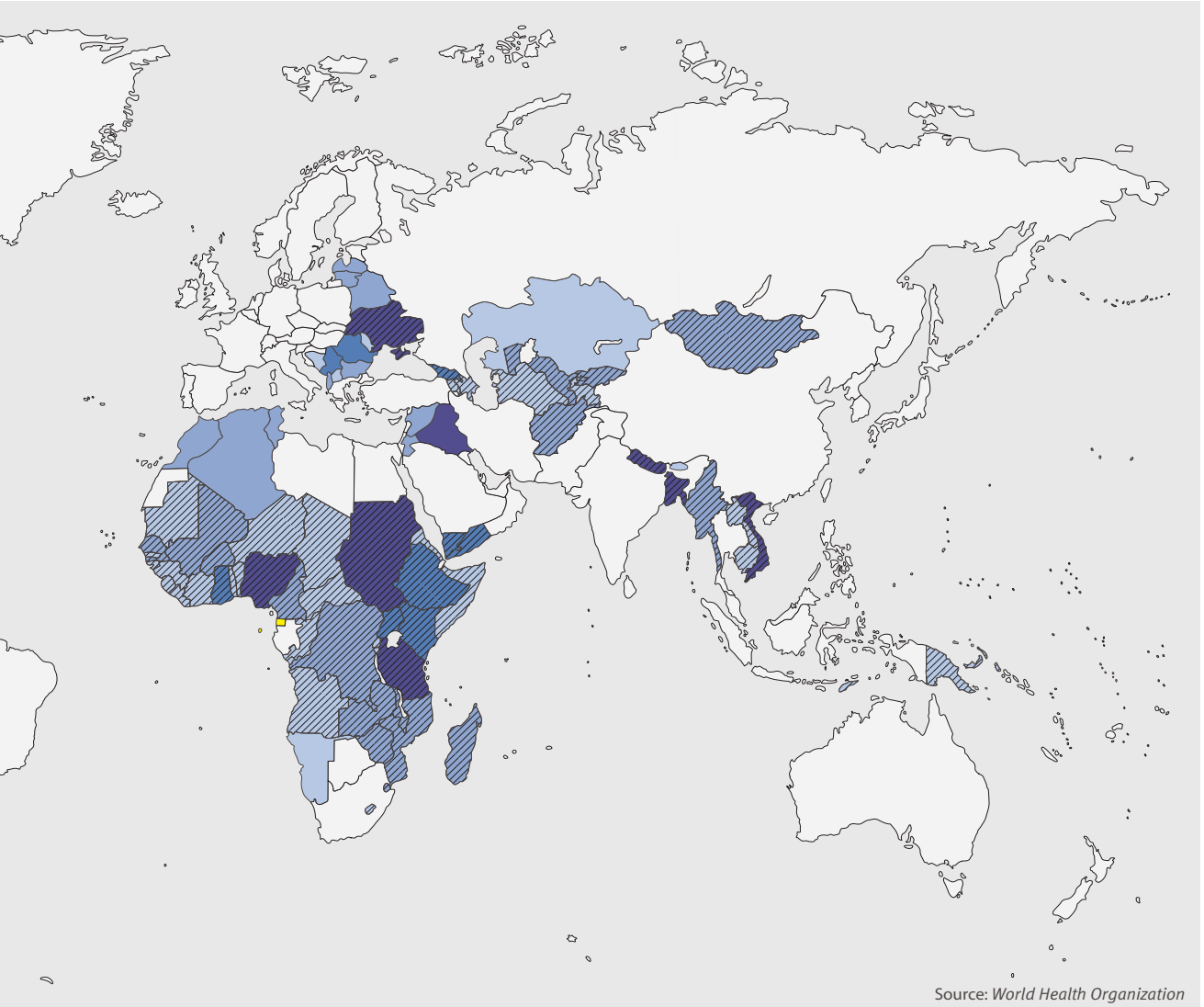

In institutions that register for the content, librarians often control or restrict access so researchers cannot use the system as freely as they need. So are developing countries' scientists and healthcare workers really getting a good deal?

HINARI was conceived as a way of helping WHO better meet the information needs of researchers. "We got several people together for a workshop, after a questionnaire had been sent out and researchers were unanimous that the one thing they needed was access to journals. So we set about doing something about that," explains Aronson. HINARI offers a simple user interface over the web serving as a gateway to full-text journal articles at publishers' websites that can be accessed directly from PubMed. ${ }^{2}$

As the only surviving element of Kofi Annan's internet commitment in the UN millennium declaration-which pledged to "ensure that the benefits of new technologies, especially information and communication technologies are available to all"-the scale of HINARI's success took even its organisers by surprise. The scheme now gives its registered users, spread among 113 countries and 2500 institutions, access to almost $80 \%$ of the published literature indexed in Medline since 2000 , and the number of available articles is now climbing towards 6200000 . Aronson believes that this growth is explained by the fortuitous timing of the launch, which capitalised on both the growing importance of the internet as an information resource and the changing nature of the publishing industryfrom one which delivered printed products to readers to a much broader information distribution business.

Maurice Long, former head of developnow publisher coordinator for HINARI and its sister projects AGORA (for agricultural literature) and OARE (environmental material), says there was an opportunity in 2000 where one had not previously existed: "In the mid1990 s, we calculated that it would cost $£ 80$ to send a free copy of the $B M J$ to an institution in a developing country." But with the internet that cost was suddenly gone.

An editorial published simultaneously by the editors of the Lancet (Richard Horton), BMJ (Richard Smith), and BioMedCentral (Fiona Godlee) in September 2000, ${ }^{3}$ calling for publishers to provide free health information to resource-poor countries, spelt out the part industry should play in taking the advantages of this new technology to the developing world. For WHO, this was all the ment at the BMJ Publishing Group and encouragement that was needed. Aronson recalls: "I rang up Richard Smith [after the editorial was published] and said 'We want to do this. Can we talk?"' She asked Smith to chair a meeting of the chief executive officers of top publishing companies. "He said he was the worst person to do it because he was a loose cannon, but instead suggested Maurice Long-and that's how he became involved."

\section{Getting the publishers to agree}

The HINARI team predicted that their biggest challenge would be getting publishers to agree to the idea of providing free content. However, even during initial negotiations in 2000, when Aronson and her team first set about approaching big publishers, the enthusiasm that would later drive HINARI's success was clear. The fact that HINARI came along at a time when the publishing industry was just starting to view the open-access movement as a commercial concern may have played a part. By mid-March, Long had managed to charm the six biggest publishers to New York for a remarkable meeting. "In the first $10 \mathrm{~min}$ utes of the meeting we had consensus," he recalls. What they decided on was a nonbinding agreement-“There are no contracts in HINARI," says Aronson-between publishers and WHO to provide their content free to developing countries.

Yale University stepped in to design an appropriate web based system for authentication and registration of HINARI's users, and in January 2002 the programme's launch was announced. After little more than a year in gestation, HINARI's birth was so quick that it led Sheldon Kotzin, executive editor of Medline, to joke about the team's tactics. Aronson reports: "He said 'How the hell did you get this done so quickly? You must have told the publishers that $\mathrm{WHO}$ was going to organise it, and they thought it would never get done and said yes," she laughs.

One issue of administrative concern was how to identify countries that should receive free access. The decision made by the HINARI team in 2000 was to delineate eligible countries according to their ranking on the World Bank development list. Those 
with a yearly per capita gross national product (GNP) of less than US $\$ 1000$ (£500:€730) were to get free access to HINARI's content, while countries with a yearly per capita GNP of $\$ 1000-\$ 3000$ were asked to pay a $\$ 1000$ fee-a sum that, according to Long, would buy "about two and a bit journals"-with that money being reinvested in training.

The aim was, and is, to get HINARI's content to as many people involved in medicine and biomedical science as possible. "We want HINARI to reach people where teaching is done, where research is done, and where policy is being made," explains Aronson. This definition includes all sorts of government offices, teaching hospitals, professional schools outside universities, national medical libraries, and occasionally non-governmental organisations. "In special cases-for example, a country like Afghanistan, where the country has contracted out the provision of health care to NGOs in whole provinces-we accept that they are the people who are providing the health care," Aronson says. "The people we don't want to have access are the local offices of Glaxo," adds Long.

\section{More than research}

HINARI provides researchers with access to scientific literature, but that is not all it does by any means. According to Aronson, the initiative has proved a spur for widening internet access in general in developing countries, thanks to the fact that anyone can register to get access for their institution or organisation. "The internet has arrived. It is just a question of giving the institutions and the ministries or organisations that fund them the incentive to get it," she explains. "Institutions] can now say to their funders, "We have access to HINARI. How about giving us a few computers?' That seems to work."

The "HINARI effect" has seen improvements in poor network connections, inadequate electricity supply, equipment shortages, and even poor English skills among staff. "From anecdotal evidence what we have seen is that, once they have HINARI, they have a reason to fix some of those problems," says Aronson. She adds that some research done by the WHO-sponsored Special Programme for Research and Training in Tropical Diseases suggested HINARI was advancing capacity building programmes, such as training in ethics and techniques for research, by 10 years.

The training that HINARI's decentralised network provides-which is essential for many first-time users who may have used the internet only for email-is also helping to improve internet literacy in developing countries. Training courses lasting four or five days familiarise institutional representatives with different publishers' web interfaces, searching, categorisation, and downloading, along with general internet concepts such as browsing, evaluating health information, and useful sources such as WHO and PubMed. "Everywhere we do training there is a burst in use," says Aronson.

However, recent surveys of users of HINARI in five African countries, done by Helen Smith and colleagues from the Liverpool School of Tropical Medicine, suggest that there are bottlenecks within institutions that prevent researchers taking full advantage of the free content. ${ }^{4}$ Part of the problem, according to Smith, is that obtaining HINARI access requires institutions to register with $\mathrm{WHO}$ and obtain a password, which must subsequently be disseminated to researchers. The password often does not work when users attempt to download articles that should be free, and some librarians discourage users from requesting full-text access. "Our research suggests that librarians control access by keeping the HINARI password and insisting users go through them for access," explains Smith. The HINARI team at WHO counters that they encour-

\section{Clinical competence in the developing world does not necessarily involve applying the most recent reasearch findings to practice}

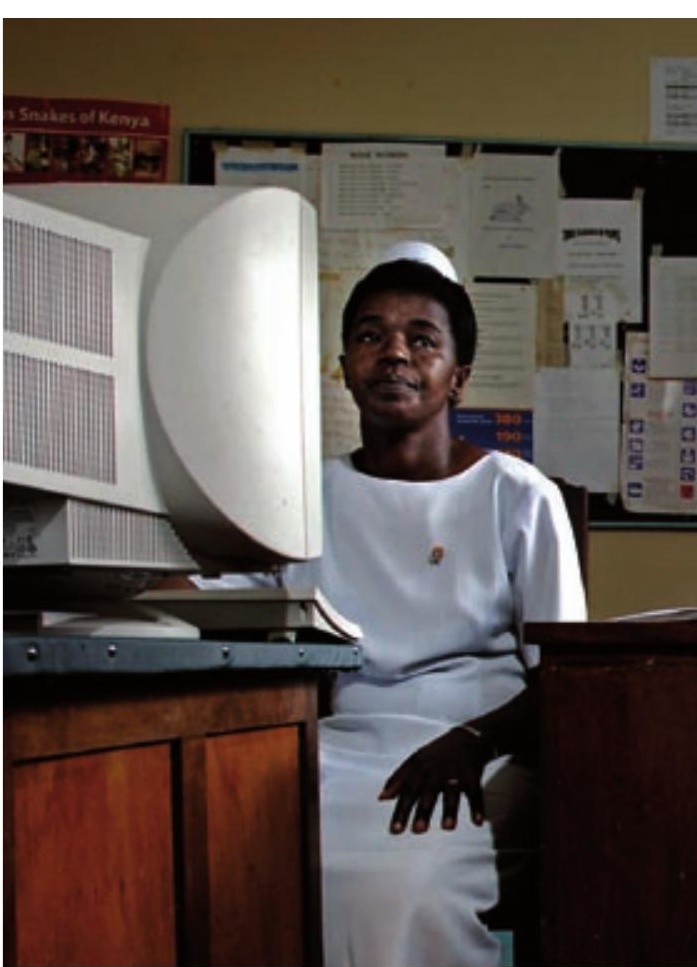

Translating the research: nurses using computers in a Kenyan hospital

improving health and health care. According to Neil Pakenham-Walsh, coordinator of the Global Healthcare Information Network and a long-time observer of HINARI, although it is incredibly important for the health system at all levels to be managed by people that are fully informed (as HINARI allows), if health workers don't have access to the information they need at the point of care then the direct health benefits are limited.

Smith and colleagues' study of electronic access to health knowledge confirms that, when it comes to treating the sick, journal articles are not the sort of information that health age dissemination of the passwords as widely as possible, but when Smith and colleagues questioned several potential users about their awareness of online services and internet use, they found that librarians are often not publicising the fact that the content is available-a particular problem for researchers who use internet cafes as their main source of internet access-and uncovered numerous examples of passwords not providing the access they should.

\section{Does HINARI advance health?}

A broader issue of concern is whether HINARI's efforts to disseminate medical science to researchers in developing countries is actually workers refer to during their day to day work: generic formularies or textbooks are more likely to guide clinical decision making. ${ }^{4}$ They explain this finding indicates that clinical competence in developing countries does not necessarily involve applying the most recent research findings to practice. Pakenham-Walsh believes it also exposes an information gap: "The whole issue of availability of health information is much broader than what HINARI is doing. They are setting an important foundation for a future when every person worldwide will have health information necessary to improve health. But researchers and academics are a very small proportion of those who need information." 
